\title{
ENTREVISTA IMAGINARIA CON MARIO LEVRERO
}

\author{
POR \\ MARIO LEVRERO \\ Buenos Aires
}

A Lisa Block de Behar, quien maquinó esto

M.L.

Mario Levrero nació en Montevideo, el 23 de enero de 1940. Empezó a conservar lo que escribía en 1966, por consejo y aliento de Tola Invernizzi. Ha publicado algunos libros (fundamentalmente narrativa) y, con diversos seudónimos, artículos periodísticos, en su mayoría humorísticos, e historietas y juegos de ingenio. En 1985 se trasladó a Buenos Aires, donde actualmente tiene a su cargo la jefatura de redacción de una revista de crucigramas.

Nos recibe, con evidente malhumor, en su apartamento próximoal Congreso. Nos hace pasar a un amplio ambiente casi desprovisto de muebles y sin ningún adorno en las paredes, en el que se destacan un centro musical, un pequeño escritorio con una gran máquina de escribir eléctrica, y el sofá-cama, en estos momentos cumpliendo su función de sofá, donde nos invita a sentarnos mientras nos prepara un café.

Se le nota cansado. Representa unos diez años más de los casi 48 que declara tener. Preparamos nuestro grabador mientras él coloca un cassette en el suyo y regula el volumen para que la música - un excelente jazz-no perturbe la conversación. Comenzamos:

E: ¿Qué es, para vos, la literatura?

ML: Es el arte que se expresa por medio de la palabra escrita.

$\mathrm{E}:$ ¿Y qué, entonces, el arte?

ML: Es, a mi criterio, el intento de comunicar una experiencia espiritual.

E: Deberías explicar, entonces, a qué llamás "experiencia espiritual".

ML: A cualquier experiencia, en la medida que pueda advertir en ella la presencia del espíritu o, si lo preferís, de mi espíritu. Y antes de que vuelvas a intercalar una de tus preguntas, me apresuro a ampliar el concepto: el espíritu es algo viviente inefable, algo que forma parte de las dimensiones de la realidad que caen habitualmente fuera de la percepción de los sentidos y aun de los estados habituales de conciencia. 
E: De modo que la literatura es una de las formas posibles de comunicar a otros seres una experiencia personal que cae fuera de las formas habituales de percepción.

ML: Yo diría que has captado exactamente lo que quise decir; casi con las mismas palabras.

E: Pero esta definición tuya, ¿no dejaría afuera de la literatura muchas obras que son consideradas como literatura?

ML: Posiblemente.

E: De modo que estarías negando la calidad literaria de obras tales como...

ML: De ninguna manera. Me preguntaste qué era para mí la literatura; no pensé en ningún momento en la literatura ajena. De todos modos, también hablé de cualquier experiencia. Creo que en las experiencias más triviales y cotidianas hay material artístico; la condición es que en ellas esté presente el espíritu del artista. Por ejemplo, yo puedo estar parado en una esquina mirando el semáforo, a la espera de que cambie la luz para cruzar la calle. De hecho estoy en esa situación varias veces al día. $Y$ alli puede haber una experiencia espiritual; depende de qué pasa conmigo mientras estoy parado en esa esquina. O podría decírtelo de una manera completamente inversa, tal como recuerdo haberlo leído hace muchos años en Charle Baudouin, en un libro que da la impresión de haber sido injustamente desestimado, Psicoanálisis del arte: lo que se percibe en una obra de arte es el alma del artista, toda ella en su conjunto, por fenómeno de comunicación alma-alma entre el autor de la obra y quien la recibe. La obra de arte sería un mecanismo hipnótico, que libera momentáneamente el alma de quien la percibe y le permite captar el alma del autor. No importa cuál sea el asunto de la obra.

E: De modo que lo esencial del arte sería la comunicación.

ML: Sí.

E: Pero hay otras formas de comunicación, además del arte.

ML: Desde luego. El arte atiende a ciertos niveles de comunicación, a los más profundos. Sin embargo, esos niveles también pueden darse de otra forma; por ejemplo, en una conversación, en la medida que haya "hipnosis", es decir, cierto encantamiento (que no es el caso de esta conversación nuestra).

E: Ese sería el caso de la conversación.

ML: No se me había ocurrido. Supongo que sí.

$\mathrm{E}:$ ¿Te molesta la entrevista?

ML: No más que otras. Pero me estoy aburriendo un poco.

$\mathrm{E:}$ ¿Qué te preguntarias, si tuvieras que entrevistarte a vos mismo?

ML: Bueno ..., hay tres clases de entrevistadores: los de tipo periodístico, los del tipo académico, y los de un tipo que mezcla dos dos anteriores. Los primeros buscan la vuelta de lo novedoso, lo llamativo, algún detalle que, creen ellos, pudiera atraer la atención del lector común. Éstos son los que más insisten en el tema de "los raros" en la literatura: Por qué alguna vez la crítica me consideró un escritor "raro", etc. Sería mucho más interesante para ellos si, en 
vez de escribir, yo hubiera, por ejemplo, cometido algún asesinato. Los del segundo tipo tienen interés en que yo me sitúe exactamente en una especie de diagrama histórico sociológico, como si ése fuera un trabajo mío y no de ellos. Pero una vez, curiosamente, fui reporteado por un señor que había leído mis libros, y se interesó mucho por mi vida personal y por mis mecanismos creativos, y por la relación entre ambas cosas. Lamentablemente no vi todavía la revista donde salió publicado, de modo que ignoro cuál es el producto final; pero me pareció que la intención era buena y, por lo menos, original. Si yo tuviera que hacer una entrevista, creo que intentaría ajustarme a la fórmula de este señor quien, por otra parte, noentra en ninguna de las tres categorías que mencionaba antes.

E: Podríamos probar con eso de los mecanismos de la creación.

ML: Puede ser, aunque es una expresión bastante desafortunada. Tal vez debí decir "la alquimia" de la creación.

E: De acuerdo. ¿Cómo sería, pues, en tu caso, este proceso de alquimia?

ML: Bueno, por definición son procedimientos secretos, ocultos. En realidad yo no trato de ocultar nada, pero no tengo un acceso directo a ellos. Es como la digestión: yo "hago" la digestión de los alimentos. pero no sé cómo.

$\mathrm{E}$ : Supongo que, en primer lugar, elegís un tema ...

ML: No, el tema, o más bien el asunto, suele elegirme a mí. En determinado momento, sin que esté pensando necesariamente en términos de literatura, percibo que hay algo que me está molestando: una imagen, una serie de palabras, o simplemente un clima, una atmósfera, un ambiente. El ejemplo más claro sería el de la imagen o el clima de un sueño, al despertar por la mañana; a veces uno se queda un buen rato como enredado en ese fragmento de ensueño; a veces eso se disipa después de un rato y a veces no. Puede volver, espontáneamente, o evocado por algo, en otros momentos del día. Cuando esto se mantiene durante varios días, es para mí una señal de que allí hay algo que es imprescindible atender, $y$ el modo de atenderlo es recrearlo. Por ejemplo: tengo un relato, "El crucificado", que nació de una perturbación de este tipo, aunque no provenía de un ensueño. Noté que desde hacía unos días tenía un crucificado en la mente, alguien que estaba permanentemente con los brazos abiertos. En realidad no descubrí que se trataba de un crucificado hasta que me detuve a examinar esa imagen perturbadora, porque era alguien que estaba vestido, se notaba claramente que tenía puesto un saco viejo. Examinándolo, descubri que debajo del saco estaba clavado a restos de una cruz de madera, y en seguida me puse a trabajar en ese relato. Otro relato, "Las sombrillas", surgió de una frase escuchada en un sueño: "Nohaymar". En el sueño, una niña saltaba sobre una cama y decía algo así como "nohaymar", o más bien yo escuchaba "noaimar". Mientras me duchaba me vino esa imagen y esa frase, y concluí que quería decir "no hay mar" y al terminar de ducharme ya tenía un relato bastante estructurado. También la novela Desplazamientos surgió de la breve escena de un sueño: una mujer en ropas menores que lavaba platos en una 
cocina. Me llevó como dos años sacar a la luz todo el mundito que encerraba esta imagen. Y por si te interesan los fenómenos parapsicológicos, te cuento una anécdota acerca de "no hay mar": días después de escrito el cuento, me encuentro con un amigo que me cuenta que, más o menos simultáneamente, él a su vez había estado escribiendo un cuento, y que se le había infiltrado un personaje con una fuerza obsesiva. Este personaje se llamaba Mariano. Como te habrás dado cuenta, "Mariano" es un perfecto anagrama de "no hay mar".

E: Cuando te referís a"examinar" una imagen, o lo que sea, ¿Qué querés decir exactamente?

ML: Prestarle atención, o permitirle que viva su vida. Y tratar de hacer conciencia de esa vida. Cuando, como ahora, no tengo tiempo de escribir, trato entonces de recrear el fragmento de un sueño o lo que sea cerrando los ojos, evocando esa imagen o clima y dejando la mente libre para que surjan asociaciones. Allí ocurre un desdoblamiento, un estado reflexivo, de modo que por un lado puedo asociar y por otro prestar atención consciente a esas asociaciones. Así es posible liberarse de lo que podría seguir molestando u obsediendo.

E: ¿De qué modo?

ML: Llegando a comprender el mensaje del llamado "inconsciente", por lo general se relaciona con hechos importantes en la vida de uno que uno ha dejado pasar sin ocuparse ellos, sin tomar conciencia de su verdadera importancia. Claro que ésta es una forma bastante superficial de autoterapia; pero me es útil.

E: ¿La literatura, seria para vos, entonces, una forma de terapia?

ML: No simplifiquemos las cosas. Yo estaba hablando de una forma particular de disipar una molestia que puede llegar a ser obsesión, que suelo aplicar cuando no puedo escribir. Cuando puedo escribir, el fenómeno se vuelve más complejo. La recreación del fragmento del sueño, de la imagen o del clima perturbador, cualquiera sea su origen (que de todos modos, siem pre es el mismo: viene del llamado "inconsciente"), ya no es el intento de disipar la molestia atendiendo a un reclamo en lo que tiene de urgente e inmediato, sino de profundizar y extender ese clima para rescatar toda una historia, un pequeño mundo, algo que podríamos llamar "una experiencia completa"; sólo que ya no se trata del "inconsciente" actuando como en un sueño, libremente, sino que hay una interacción con la conciencia, la que tiene sus exigencias de una lógica vigil, de coherencia con la vigilia. Las asociaciones son, por así decirlo, perturbadas por la conveniencia, limitadas, controladas, hasta cierto punto dirigidas o estimuladas. El resultado final puede ser más o menos largo o breve, pero siempre es algo completo.

E: ¿Y eso resuelve el problema?

ML: ¿De la perturbación? Creo que sí, porque la perturbación desaparece. Pero probablemente crea otros problemas, y también probablemente resuelva otros problemas. A veces pasan años antes de que comprenda la relación entre un texto determinado y las cuestiones personales con las que está ligado, qué fue 
lo que resolví o lo que intenté resolver con ese texto. Muchas veces no descubro nada; el texto parece tener una vida propia, bastante ajena a la mía. Pero, de todos modos, no es ésa la intención literaria; no se trata, como decías, de una forma de terapia. Hace un rato hablábamos de comunicación. Ya no soy yo, a solas con la perturbación, buscando liberarme de ella, sino que soy yo tratando de comunicarme, creando un estructura que me represente ante otro ser.

E: ¿Te dirigís a alguien en particular, o pensás en un público en general?

ML: He descubierto que todos mis textos tienen un destinatario preciso, aunque no siempre sea consciente de ello. Siempre hay alguien a quien deseo contarle algo; cuando estoy escribiendo, estoy con la mente puesta en una persona determinada.

E: ¿Siempre es la misma?

ML: No, casi nunca, o nunca, dos veces la misma.

$\mathrm{E}: ¿$ Esto no condiciona en alguna medida tu lenguaje?

ML: Seguramente. Uno no se dirige del mismo modo a todo el mundo. $Y$ probablemente no sólo el lenguaje, sino también las imágenes, todo.

E: Hablabas de cierta relación entre un texto y tu vida personal. ¿Esto debe entenderse como formas autobiográficas de narración?

ML: Eso depende de tu concepto de "autobiográfico". Yo hablo de cosas vividas, pero en general no vividas en ese plano de la realidad con el que se construyen habitualmente las biografias.

E: ¿No es una forma un poco retorcida de calificar a tu literatura de "imaginaria"?

ML: La imaginación es un instrumento; un instrumento de conocimiento, a pesar de Sartre. Yo utilizo la imaginación para traducir a imágenes ciertos impulsos - llámalos vivencias, sentimientos o experiencias espirituales. Para mí esos impulsos forman parte de la realidad o, si lo preferís, de mi "biografía". Las imágenes bien podrían ser otras; la cuestión es dar a través de imágenes, a su vez representadas por palabras, una idea de esa experiencia íntima para la cual no existe un lenguaje preciso.

E: Por ejemplo, ¿tus personajes son extraídos de la vida real?

ML: A veces, los tomo prestados de eso que llamás "la vida real" más bien en fragmentos, comoen un collage. En general, mis personajes están compuestos de varias personas que conocí. Pero en los textos no son quienes son; no son más que imágenes, insisto. No pretendo que nadie los sienta como de carne y hueso; más bien parecen de cartón.

E: Hay quienes sienten tus textos como versiones de una realidad deformada, exagerada, cruel, absurda, pesadillesca, asfixiante ....

ML: Puedo aceptar todos esos calificativos menos uno: "deformada". Ese suele ser un recurso de la ciencia-ficción. Yo no hablaría de "deformación de la realidad" en mis textos, sino más bien de subjetivismo... Me hacés pensar en los zapatos que están en una vidriera y en los zapatos "deformados" por el uso. ¿Le llamarías "deformados" a los zapatos que usás? ¿Son más "reales" los de la vidriera? 
E: Decías que actualmente no estás escribiendo. ¿Por qué?

ML: Sabés muy bien que estoy trabajando.

$\mathrm{E}:$ ¿Y el trabajo es incompatible con la creación literaria?

ML: En mi experiencia, al menos hasta ahora, sí. No soy un escritor de fines de semana. Escribir no es sentarse a escribir; ésa es la última etapa, tal vez prescindible. Lo imprescindible, no ya para escribir sino para estar realmente vivo, es el tiempo de ocio. Mediante el ocio es posible armonizarse con el propio espíritu, o al menos prestarle algo de la atención que merece. Yo no soy escritor profesional, no me propongo llenar tantas carillas, y no quiero ni puedo escribir sin la presencia del espíritu, sin inspiración. Aquí tengo un texto de Raymond Chandler, en realidad una carta de Chandler:

leo constantemente cómo los autores dicen que jamás esperan que llegue la inspiración: lo que ellos hacen es sentarse a sus escritorios todas las mañanas a las ocho, con lluvia o sol, con los restos de una borrachera, un brazo roto, o lo que sea, y vomitan su pequeña cuota. No importa cuán en blanco estén sus mentes o cuán agarrotados su cerebros, nada de absurda inspiración con ellos. A ellos entrego mi admiración y mi cuidado de evitar sus libros.

Mirá, yo soy muy haragán; me pongo a escribir cuando me resulta imperioso, o ineludible, del mismo modo que me pongo a hacer cualquier otra cosa cuando me resulta imperioso e ineludible. Vivo de stress en stress. Mi ideal de vida es el reposo absoluto. Para que me ponga a hacer algo hace falta un estímulo, y en el caso de la literatura es necesario un estímulo a dos puntas: la necesidad de sacar algo a la luz, y la necesidad de comunicarlo a alguien. En estos momentos, estos estímulos no están presentes o bien son muy débiles frente a otros, como puede serlo la necesidad imperiosa de sobrevivir en un medio muy difícil.

E: ¿Pero en este tiempo de vida bonaerense no has sentido necesidad de escribir?

ML: No en los comienzos, pero sí últimamente. $\mathrm{Y}$ cada vez con mayor fuerza. Por otra parte, tengo ganas de contar muchas cosas vividas; sin embargo, no sólo no puedo contarlas, sino que ni siquiera puedo pensarlas; vivo las cosas muy superficialmente, sin tiempo para asimilarlas, asentarlas. Por eso casi he perdido la medida del tiempo. El primer año pasado en Buenos Aires ( $y$ por ende en mi trabajo de oficina) me pareció no contener más que una o dos semanas. Era como un tiempo sin sustancia, de mala calidad. Ahora hay algo de eso, pero de algún modo misterioso me las he arreglado para sentir que el tiempo tiene más consistencia. Este último año ha sido bastante parecido a un año. De cualquier manera, al estar en cierto modo divorciado de mi "inconsciente", toda experiencia, aun la de apariencia más compleja y atractiva, la siento incompleta, como que me estoy perdiendo algo esencial Hubo una serie de experiencias notables, a las que por suerte pude rescatar, "darles consistencia", escribiendo o bien breves pasajes, tipo diario íntimo, o bien cartas a algunas 
amistades. Pero es todo muy fragmentario y muy "actual"; me está faltando la literatura.

E: Podríamos decir que es algo así como que "lo que no escribís, no lo vivís?

ML: Algo así; tal vez no tan extremo, pero algo así. Por lo menos, "lo que no pienso no lo vivo". Pero me consuelo pensando que podré pensarlo después, rescatarlo.

E: ¿Cómo situarías tu literatura en el panorama de la literatura uruguaya contemp...?

ML: Oh, oh. Tú también, Bruto.

E: Perdón. Sólo quería sacarte un momento de tu monólogo narcisista.

ML: ¿Por qué?

E: Bueno ..., yo ..., es decir ...

ML: Vos querés sacarme de mi punto de vista personal; y situarme en un punto de vista, digamos académico. Me extraña que caigas en el mismo error de otros reporteros; pensé que me conocías mejor.

E: En realidad te estaba provocando, para que confesaras nuevamente la endeblez de tu formación cultural.

ML: Eso no me molesta. Lo confieso. Podría además confesar la endeblez de mi formación en una cantidad enorme de materias. Pero es cierto: mi desconocimiento de la literatura es, o debería ser, vergonzoso. Creo que se debe a la falta de disciplina; soy, tal vez, demasiado hedonista, y tiendo a leer lo que tengo ganas de leer y no lo que debería leer; también prefiero leer a los que escriben y no a los que escriben sobre los que escriben. Aborrezco los catálogos, las enumeraciones, los análisis, las interpretaciones; por otra parte, siento que el punto de vista crítico me aleja de la obra de arte, en lugar de acercarme; que me obliga a leer un libro con un solo ojo, por así decirlo.

E: ¿Y con el otro?

ML: Con el otro voy leyendo entre líneas: aquí, donde dice lo que dice, el autor en realidad quiere decir ... Eso me impide caer en trance. Me impide recibir el alma del autor, para usar el lenguaje de Baudouin. Es más, creo que ésa es la verdadera función de la crítica: impedir que la locura contenida en una obra se contagie como una peste a toda la sociedad. Es una función represora, de tipo policial, y no quiero decir que eso esté mal; creo que es necesaria. Pero personalmente me fastidia, porque da la casualidad de que me están reprimiendo a mí, o por lo menos a lo que yo escribo. Están acotando, poniendo barreras entre el lector y el autor. Esto, desde luego, termina por favorecer incluso a la literatura, le permite crecer, buscar nuevas formas de decir lo suyo -del mismo modo que la función policial permite que evolucionen las formas del crimen.

E: Hay otras formas de terminar con la literatura ...

ML: Sí. El negocio editorial. Pero no me preocupa. No me preocupa el libro en si ni la literatura en sí. Me preocupa la comunicación, pero como es una necesidad vital estoy seguro de que siempre encontrará la forma de manifestarse.

E: Es que, en esencia, no sos un literato. 
ML: No, no cultivo las letras, sino las imágenes; y las imágenes están muy próximas a la materia prima, que son las vivencias. Pero hemos vuelto al "monólogo narcisista", aunque para mi gusto no es tal, sino más bien un "monólogo introvertido", que no es lo mismo. Cuando me meto dentro de mí mismo, lo que encuentro allí es también el mundo exterior, sóloque transmutado en un "lenguaje" que me permite percibirlo mejor.

E: Te propongo volver al tema de la literatura uruguaya, desde este nuevo ángulo" ¿Has leído algo, últimamente, de autores uruguayos?

ML: Estuve leyendo a Onetti y a Leo Maslíah. Los extremos, podríamos decir.

$\mathrm{E}:$ ¿Y?

ML: Bueno, Onetti siempre me exige un gran esfuerzo. Es uno de los autores que justamente no tienen "encanto", no te hipnotizan o no te permiten caer en trance; Onetti lleva a su propio crítico incorporado, sabe crear una distancia casi insalvable para el lector; te obliga a leerlo con un solo ojo.

$E$ : Me extraña entonces que lo leas.

ML: Hay una razón: por algún motivo, cuando de tanto en tanto caigo en una "crisis literaria", tengo algún sueño en el cual aparece el "Escritor", una figura imponente, una especie de maestro, grande y oscuro, al cual me acerco; no nos hablamos, él simplemente está allí, en una actitud de contemplación o ensimismamiento, y yo me mantengo a una respetuosa distancia, lo observo. No sucede más nada, pero esos sueños tienen una carga tremenda y sé que en ellos resuelvo algo que me permite seguir andando. Bien, en el sueño no se dice de un modo explícito, pero al despertar sé que ese hombre es Onetti. Y hay otra razón: por más que habitualmente sea haragán para leer, no lo soy siempre. A veces tengo ganas de leer con esfuerzo, o atención. Y con Onetti vale la pena.

E: ¿Y Maslíah?

ML: Me represento a Leo como un violinista tocando en un violín con una sola cuerda. Me maravilla todo lo que puede hacer con una sola cuerda. Por otra parte, también me obliga a un esfuerzo, y voy leyendo y pensando que me gustaría que acá hiciera esto y más allá esto otro, pero supongo que eso es una especie de deformación profesional mía. Al mismo tiempome divierte muchísimo, me entretiene tanto como una novela policial, o más. Algo parecido me pasa con Beckett. No sé, creo que Leo está tratando de reventar la literatura, y que eso es sano, que forma parte de un proceso renovador; pero después pienso que esa aceptación mía no es tan natural y espontánea, que me duele que reviente la literatura y que estoy demasiado viejo para sentirlo de otra manera.

$\mathrm{E}:$ ¿Y qué otra cosa has leído en los últimos tiempos?

ML: Novelas policiales. Toneladas de novelas policiales. Y bastante Henry Miller, aunque salteando muchas páginas; a veces sólo puedo rescatar un capítulo genial de todo un libro; a veces son fragmentos de capítulos sueltos. De todo lo que he leído de Miller, creo que sólo Trópico de Cáncer tiene el equilibrio perfecto. Claro que ya es mucho.

E: ¿Por qué las novelas policiales? 
ML: Es lo que me resulta más eficaz como escape de la realidad. Y antes de que me preguntes por qué deseo escapar de la realidad, te recuerdo que estoy viviendo un tiempo de autosecuestro: me estoy obligando a trabajar para ganarme la vida, porque hace ya bastante tiempoque las condiciones de nuestro país no permiten la subsistencia marginal que, en su momento, me permitió escribir.

$\mathrm{E}$ : ¿Tus autores policiales favoritos?

ML: Chandler, a quien releo bastante seguido, lo mismo que a Simon Himes, Rex Stout, Anthony Gilbert, Dickson Carr y una larga lista, tanto en el género clásico inglés como en la novela negra.

$\mathrm{E}:$ ¿No te decepcionan las novelas policiales?

ML: Una a una, sí; prácticamente todas. Pero, curiosamente, como género, no. La decepción suele darse al final (si se da al principio, no sigo leyendo) cuando uno descubre que toda su atención fue captada y sostenida, a menudo en forma magistral, durante algunas horas, para quedarse con las manos vacías. Exactamente igual que con los crucigramas o los problemitas lógicos. Sin embargo, esa decepción debe encubrir sentimientos de culpa o algo así, porque en el transcurso de las novelas uno recibe muchas cosas disfrutables. El problema insoluble de la novela policial es que debe ser necesariamente una novela "cerrada"; los enigmas planteados deben quedar perfectamente resueltos, porque si no la novela fracasa y produce ira, 0 un sentimiento de estafa, $o$ ambas cosas. Y una novela "cerrada" deja una sensación de vacío, porque no tiene la menor capacidad de movilizar al lector. Te angustia, y te saca la angustia que te creó; no te deja una angustia libre que puedas aprovechar para modficar tu vida como sucede con la verdadera literatura.

E: ¿La novela policial ha influido en tu literatura?

ML: Para algunos críticos, sí. Yo también supongo que sí. Suelen citarse fuentes más o menos innobles de mi literatura, la novela policial entre ellas. También se ha citado la pornografia, aunque es un error: detesto la pornografía. Otro error es buscar fuentes exclusivamente literarias para la literatura, como si un fabricante de quesos tuviera que alimentarse exclusivamente de quesos. Antes de escribir traté de hacer cine, hasta que me di cuenta de que en Uruguay era imposible. Terminé escribiendo porque era mucho más barato, y porque me faltó disciplina para aprender música o pintura o para ser médico o psicólogo. Después que uno encuentra un modo de expresión, se le hace fácil y cuesta salirse de él, pero no quisiera descartar del todo la posibilidad de empezar de vuelta, con otro medio de expresión. Tampoco quisiera descartar del todo la posibilidad de no hacer nada. Pero me llama la atención esa miopía generalizada, ese afán de construir un mundo coherente pero falso donde todos los escritores están como pinchados con alfileres en un mapa, en una red de parentescos e influencias. Creo que el cine, la música, los amigos, las mujeres, las hormigas, el mar, y etcétera, me han influido tanto o más que los libros.

E: A propósito de pornografía y de mujeres: independientemente de 
opiniones ajenas, coincidirás conmigo que en tu literatura hay una fuerte carga sexual a menudo expresada de un modo bastante directo, por no decir bruto. ¿No hay una contradicción entre este hecho y tu declaración, al principio de la entrevista, acerca de la "experiencia espiritual" que debería transmitir la literatura?

ML: En absoluto. La contradicción está en ciertos dogmas religiosos que quieren separar, aislar, al espíritu. Yo creo que la experiencia erótica es esencialmente espiritual, y que por ese mismo motivo es algo prohibido. Es más, la actual "liberación sexual" no hace más que acentuar la contradicción del dogma y acentuar la prohibición de lo espiritual.

$\mathrm{E}:$ ¿No es exactamente al revés?

ML: No. Estamos en un momento de un extremo imperio del materialismo. Se permite el sexo en tanto se mantenga estrictamente en los límites del materialismo. El erotismo, o sea la comunicación, sigue prohibido. Por eso florece la pornografía, y el arte erótico sigue marginado. También el ocio se hace cada día menos posible y más sospechoso. Todo esto augura un próximo florecimiento espiritual; no hay, como decía Lao-Tsé, más que llegar a lo más alto para empezar a caer. Y ya que citamos, dejame recordar aquellos versos de Ezra Pound que fueron el lema de la efímera revista Opium: "Cantemos al amor y al ocio / que nada más merece ser habido".

ML: Volviendo a tu pregunta, no creo, por otra parte, que las referencias sexuales en mi literatura sean más directas o más brutas que el resto de las referencias; probablemente se noten más, pero te habrás dado cuenta de que no soy un estilista ni, en general, ando dando rodeos para decir las cosas.

E: ¿Qué opinás de la literatura comprometida?

ML: Como subgénero, no me atrae. Prefiero la novela policial.

E: ¿Porque la literatura comprometida te enfrenta justamente con esa realidad de la cual querés escapar?

ML: No, yo sólo quiero escapar de la realidad de mí mismo - en ciertas circunstancias, cuando no tengo oportunidad de trabajar con ella. No, lo que no me atrae de la literatura "comprometida" es que, por lo general, hay más "compromiso" que literatura. Participa de un mecanismo similar al de los best sellers: se escriben libros para que los compre determinado público, y no con intención de establecer esa comunicación que define al arte.

E: ¿Esta opinión no te sitúa políticamente a la derecha?

ML: Hay gente de izquierda que me ha dicho que conmigo no se puede hablar porque soy "demasiado rebelde". En realidad, mi posición política es variable; suele situarse habitualmente en el polo opuesto de la de mi interlocutor -cualquiera sea su posición, lo cierto es que no entiendo nada de política, y que cada vez entiendo menos. Y no sólo de política; cada vez entiendo menos, en general. No conozco ninguna verdad; creo que el mundo debería estarme agradecido por haber abandonado hace muchísimos años toda pretensión de mejorarlo.

No conozco las ideas fijas. Uno de mis grandes placeres es reconocer mis 
errores. No confío en las ideas; son como una jaula. Pero, volviendo a la literatura "comprometida", no hay excepciones, desde luego. Hay obras maestras "comprometidas", por lo general escritas por hombres realmente comprometidos y no por comerciantes o trepadores.

E: En más de una entrevista que te han hecho, has defendido la posición de que tu literatura es "realista". ¿Es parte del juego ése, de situarte en el polo opuesto al de tu interlocutor?

ML: Claro, me sitúo en el "realismo" cuando intentan ubicarme en la ciencia-ficción o en la fantasía.

E: ¿Dónde te ubicarias vos, entonces?

ML: ¿Por qué me querés encasillar?

E: ¿Cómo explicarias, sin recurrir a encasillamientos, cómo es tu obra, al lector de esta entrevista que no conozca tu obra?

ML: Creo que esta entrevista forma parte de eso que llamás mi "obra". Si se lee bien, aquí estoy yo, entero.

$\mathrm{E}$ : ¿Te gustan tus libros? ¿Cuál es tu autovaloración como escritor?

ML: Me gustan algunos de mis libros, a veces parte de mis libros, $y$ a veces me gustan más y a veces menos. No me leo muy a menudo, y mientras no me estoy leyendo tiendo a valorarme muy bajo. Cuando leo a otros autores, quiero decir buenos autores, tiendo a valorarme todavia más bajo. Sin embargo, a veces agarro algo mío y me atrapa, me emociona, me asombra. Me parece mentira que eso haya pasado por mí, a través mío. Es que, fuera de los períodos de inspiración, soy totalmente incapaz de escribir, y en los períodos de inspiración no soy exactamente yo mismo. Cuando leo algo mío, salvo algunas cosas que me resultan sistemáticamente aborrecibles, me parece estar leyendo algo ajeno, y al tomar conciencia de que es "mío" (quiero decir que pasó por mn), suelo quedar maravillado. Pero incluso maravillado, no me engaño. Sé que mi literatura es un arte menor. Pero también sé que es un arte. La valoro como algo auténtico.

Hablando de estas cosas, un sacerdote amigo me dijo una vez: "Lo importante no es que tu copa sea más grande que las copas de otros, sino que tu copa esté llena". Hay construcciones de catedrales que admiro y reverencio; pero por mi parte cultivo un pequeño jardín o, si preferís, algunas plantas en macetas. Bueno, también en las plantas que crecen en macetas hay motivos para maravillarse.

E: ¿Volverás a escribir?

ML: Si depende mí, seguramente. Por ahora no depende de mí.

E: ¿Qué consejo darías a los escritores jóvenes?

ML: Mirá ....

En este punto, Levrero interrumpe violentamente la entrevista, tratando de arrojarme a la cabeza su pesada IBM 82C, que, por fortuna, no daen el blanco. 
